Acta Crystallographica Section C

Crystal Structure

Communications

ISSN 0108-2701

\section{N-Benzylethylammonium nitrate: a three-dimensional hydrogen-bonded framework comprising substructures in zero, one and two dimensions}

\section{Rodrigo Abonia, ${ }^{a}$ Emerson Rengifo, ${ }^{a}$ Justo Cobo, ${ }^{b}$ John N. Low $^{\mathrm{c}}$ and Christopher Glidewell ${ }^{\mathrm{d}}$ *}

a Grupo de Investigación de Compuestos Heterocíclicos, Departamento de Química, Universidad de Valle, AA 25360 Cali, Colombia, ${ }^{\mathbf{b}}$ Departamento de Química Inorgánica y Orgánica, Universidad de Jaén, 23071 Jaén, Spain, 'Department of Chemistry, University of Aberdeen, Meston Walk, Old Aberdeen AB24 3UE, Scotland, and ${ }^{\mathbf{d}}$ School of Chemistry, University of St Andrews, Fife KY16 9ST, Scotland

Correspondence e-mail: cg@st-andrews.ac.uk

Received 3 October 2005

Accepted 5 October 2005

Online 22 October 2005

The title compound is a salt, $\mathrm{C}_{9} \mathrm{H}_{14} \mathrm{~N}^{+} \cdot \mathrm{NO}_{3}{ }^{-}$, in which two $\mathrm{N}-$ $\mathrm{H} \cdots \mathrm{O}$ hydrogen bonds and two $\mathrm{C}-\mathrm{H} \cdots \mathrm{O}$ hydrogen bonds generate a three-dimensional framework structure. The combination of one $\mathrm{N}-\mathrm{H} \cdots \mathrm{O}$ hydrogen bond and one $\mathrm{C}-$ $\mathrm{H}$.. O hydrogen bond generates a finite (zero-dimensional) centrosymmetric $R_{4}^{4}(14)$ aggregate containing two cations and two anions; the combination of the two $\mathrm{N}-\mathrm{H}$... O hydrogen bonds generates a one-dimensional $C_{2}^{2}(6)$ chain of alternating cations and anions, and the combination of one $\mathrm{N}-\mathrm{H} \cdots \mathrm{O}$ hydrogen bond and two $\mathrm{C}-\mathrm{H}$. . O hydrogen bonds generates a two-dimensional sheet of alternating $R_{4}^{4}(14)$ and $R_{8}^{6}(34)$ rings.

\section{Comment}

In an attempt to effect the selective removal of the benzotriazole residue from $N$-(benzotriazol-1-ylmethyl)- $N$-ethylbenzylamine, a methanol solution of this compound was treated at room temperature with an aqueous solution of silver nitrate, resulting in the formation of $\mathrm{N}$-benzylethylammonium nitrate, (I), as the main isolated product.

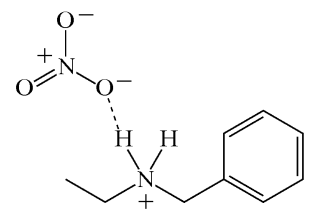

(I)

The two ionic components are linked into a three-dimensional framework structure of some complexity by a combination of two rather short $\mathrm{N}-\mathrm{H} \cdots \mathrm{O}$ hydrogen bonds, between cationic $\mathrm{N}$ and anionic $\mathrm{O}$ atoms, and two $\mathrm{C}-\mathrm{H} \cdots \mathrm{O}$ hydrogen bonds (Table 2). The formation of the framework is readily analysed in terms of several fairly simple and lowdimensional substructures (Gregson et al., 2000). A onedimensional substructure is built from $\mathrm{N}-\mathrm{H} \cdots \mathrm{O}$ hydrogen bonds only, while a combination of one each of the $\mathrm{N}-\mathrm{H} \cdots \mathrm{O}$ and $\mathrm{C}-\mathrm{H} \cdots \mathrm{O}$ hydrogen bonds generates a finite zerodimensional substructure, which itself forms the building block of a two-dimensional substructure utilizing one $\mathrm{N}-$ $\mathrm{H} \cdots \mathrm{O}$ hydrogen bond and both of the $\mathrm{C}-\mathrm{H} \cdots \mathrm{O}$ hydrogen bonds.

Within the selected asymmetric unit (Fig. 1), atom N2 in the cation acts as a hydrogen-bond donor, via $\mathrm{H} 2 A$, to atom $\mathrm{O} 1$ in the anion. In addition, atom $\mathrm{N} 2$ in the cation at $(x, y, z)$ acts as a donor, via $\mathrm{H} 2 B$, to atom $\mathrm{O} 3$ in the anion at $(-1+x, y, z)$, so generating by translation a one-dimensional substructure in the form of a $C_{2}^{2}(6)$ (Bernstein et al., 1995) chain running parallel to the [100] direction (Fig. 2).

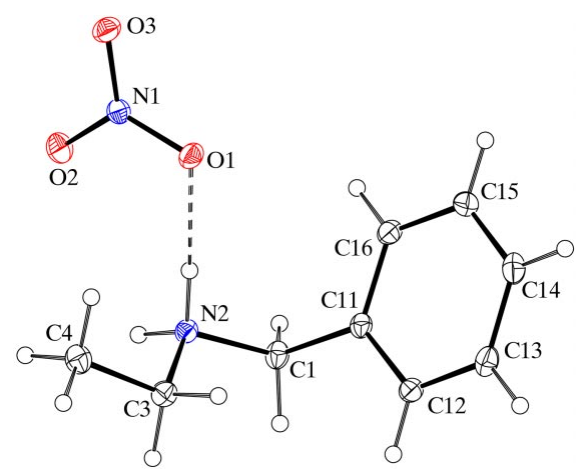

Figure 1

The independent components of (I), showing the atom-labelling scheme and the $\mathrm{N}-\mathrm{H} \cdots \mathrm{O}$ hydrogen bond (dashed lines) within the asymmetric unit. Displacement ellipsoids are drawn at the $30 \%$ probability level.

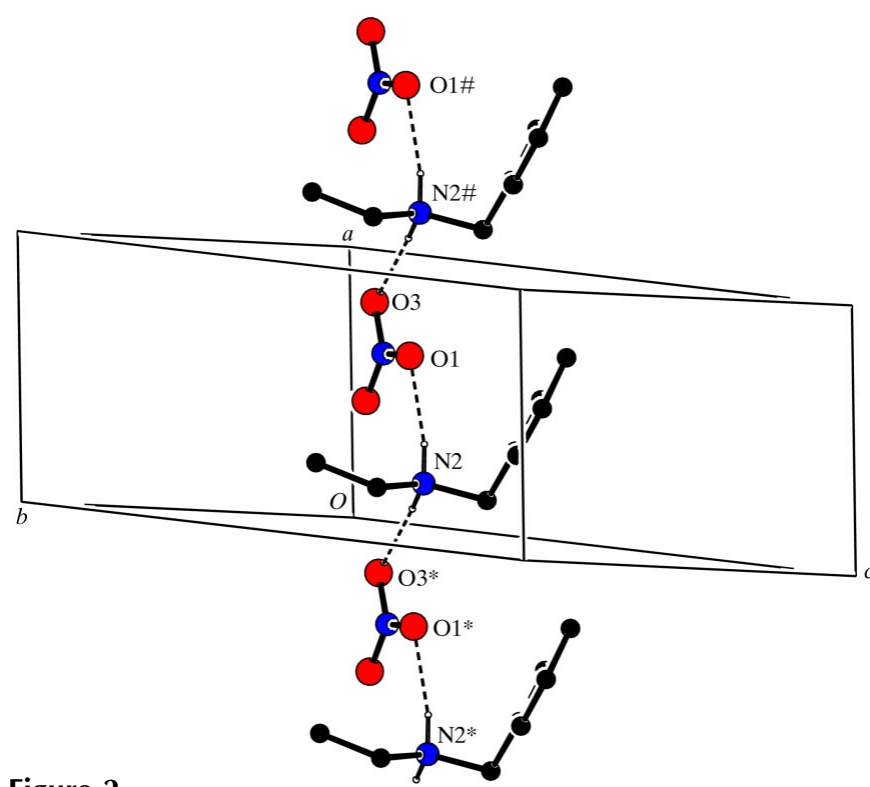

Figure 2

Part of the crystal structure of (I), showing the formation of a hydrogenbonded $C_{2}^{2}(6)$ chain along [100]. For clarity, $\mathrm{H}$ atoms bonded to $\mathrm{C}$ atoms have been omitted. Atoms marked with an asterisk $(*)$ or a hash (\#) are at the symmetry positions $(-1+x, y, z)$ and $(1+x, y, z)$, respectively. 
The action of the $\mathrm{C}-\mathrm{H}$...O hydrogen bonds leads to considerably more complexity than the rather simple motif generated by the $\mathrm{N}-\mathrm{H} \cdots \mathrm{O}$ hydrogen bonds alone. However, the analysis of the two-dimensional substructure is markedly eased by the identification of a finite centrosymmetric four-ion aggregate. Atom $\mathrm{C} 1$ in the cation at $(x, y, z)$, which is adjacent to the positive ammonium centre, acts as a hydrogen-bond donor, via $\mathrm{H} 1 A$, to atom $\mathrm{O} 3$ in the anion at $(1-x, 1-y, 1-z)$, so forming by inversion a cyclic centrosymmetric $R_{4}^{4}(14)$ aggregate containing two cations and two anions and centred at $\left(\frac{1}{2}, \frac{1}{2}, \frac{1}{2}\right)$ (Fig. 3 ); this aggregate forms the basic building block for the construction of the two-dimensional substructure.

Aryl atoms $\mathrm{C} 13$ in the cations at $(x, y, z)$ and $(1-x, 1-y$, $1-z)$, which lie in the $R_{4}^{4}(14)$ aggregate centred at $\left(\frac{1}{2}, \frac{1}{2}, \frac{1}{2}\right)$, act as hydrogen-bond donors, respectively, to atom $\mathrm{O} 3$ in the

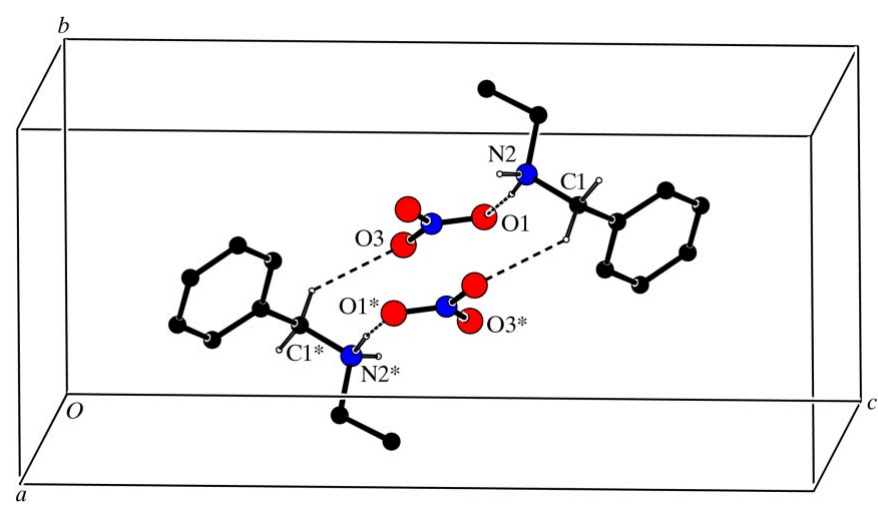

Figure 3

Part of the crystal structure of (I), showing the formation of a cyclic hydrogen-bonded $R_{4}^{4}(14)$ aggregate of two cations and two anions. For clarity, $\mathrm{H}$ atoms in the ethyl and phenyl groups have been omitted. Atoms marked with an asterisk $(*)$ are at the symmetry position $(1-x, 1-y$, $1-z)$.
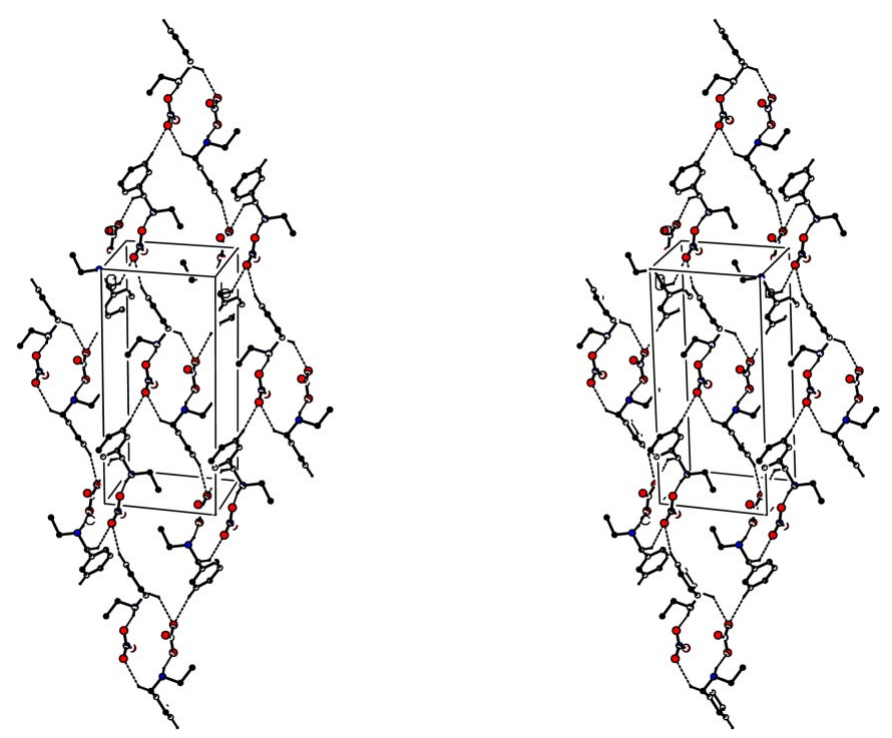

Figure 4

A stereoview of part of the crystal structure of (I), showing the formation of a hydrogen-bonded (101) sheet built from $R_{4}^{4}(14)$ and $R_{8}^{6}(34)$ rings. For clarity, $\mathrm{H}$ atoms not involved in the motifs shown have been omitted.

anions at $\left(-\frac{1}{2}+x, \frac{3}{2}-y, \frac{1}{2}+z\right)$ and $\left(\frac{3}{2}-x,-\frac{1}{2}+y, \frac{1}{2}-z\right)$, which themselves lie in the $R_{4}^{4}(14)$ aggregates centred at $(0,1,1)$ and $(1,0,0)$, respectively. Similarly, atoms O3 in the anions at $(x, y, z)$ and $(1-x, 1-y, 1-z)$ accept hydrogen bonds from atoms C13 in the cations at $\left(\frac{1}{2}+x, \frac{3}{2}-y,-\frac{1}{2}+z\right)$ and $\left(\frac{1}{2}-x\right.$, $\left.-\frac{1}{2}+y, \frac{3}{2}-z\right)$, which form parts, respectively, of the $R_{4}^{4}(14)$ aggregates centred at $(1,1,0)$ and $(0,0,1)$. Propagation by the space group of this single hydrogen bond then links each $R_{4}^{4}(14)$ aggregate to four others, so forming a (101) sheet containing alternating $R_{4}^{4}(14)$ and $R_{8}^{6}(34)$ rings (Fig. 4).

The combination of the [100] chain and the (101) sheet is sufficient to generate a continuous three-dimensional framework, within which it is possible to identify substructures in zero (Fig. 3), one (Fig. 2) and two (Fig. 4) dimensions.

The conformation of the cation is unexpected. While the $\mathrm{C} 1-\mathrm{N} 2$ and $\mathrm{C} 3-\mathrm{C} 4$ bonds are antiperiplanar, the $\mathrm{N} 2-\mathrm{C} 3$ and $\mathrm{C} 1-\mathrm{C} 11$ bonds are synclinal (Table 1 ); the aryl ring is approximately normal to the $\mathrm{C} 11-\mathrm{C} 1-\mathrm{N} 2$ plane. In the anion, it is notable that the $\mathrm{N} 1-\mathrm{O} 2$ bond is significantly shorter than the other two $\mathrm{N}-\mathrm{O}$ bonds (Table 1); in this respect, it is worth noting that atom $\mathrm{O} 2$ is the one $\mathrm{O}$ atom not involved in the hydrogen bonding. Associated with the unequal bond lengths, the $\mathrm{O} 1-\mathrm{N} 2-\mathrm{O} 3$ angle is significantly less than the other two $\mathrm{O}-\mathrm{N}-\mathrm{O}$ angles.

\section{Experimental}

An aqueous solution of $\mathrm{AgNO}_{3}$ (0.5 ml containing $0.44 \mathrm{mmol}$ ) was added dropwise at room temperature over a period of $5 \mathrm{~min}$ to a vigorously stirred solution of $N$-(benzotriazol-1-ylmethyl)- $N$-ethylbenzylamine $(0.1 \mathrm{~g}, 0.38 \mathrm{mmol})$ in methanol $(5 \mathrm{ml})$. The resulting precipitate was removed by filtration and the filtrate was evaporated under reduced pressure, yielding an oily residue. After two days, colourless crystals of (I) had formed from the oil, and these proved to be suitable for single-crystal X-ray diffraction (90\% yield; m.p. 368$369 \mathrm{~K})$. MS: $(70 \mathrm{eV}) \mathrm{m} / \mathrm{z}$ (\%) $136\left(21.5, M^{+}\right), 120$ (26.5), 91 (100).

Crystal data

$\mathrm{C}_{9} \mathrm{H}_{14} \mathrm{~N}^{+} \cdot \mathrm{NO}_{3}^{-}$

$M_{r}=198.22$

Monoclinic, $P 2_{1} / n$

$a=5.9538$ (4) $\AA$

$b=8.9940(6) \AA$

$c=18.7484(8) \AA$

$\beta=98.324(4)^{\circ}$

$V=993.37(10) \AA^{3}$

$Z=4$

\section{Data collection}

Nonius KappaCCD diffractometer

$\varphi$ and $\omega$ scans

Absorption correction: multi-scan (SADABS; Sheldrick, 2003)

$T_{\min }=0.969, T_{\max }=0.980$

13128 measured reflections

2262 independent reflections

Refinement

Refinement on $F^{2}$

$R\left[F^{2}>2 \sigma\left(F^{2}\right)\right]=0.043$

$w R\left(F^{2}\right)=0.132$

$S=1.11$

2262 reflections

128 parameters

$\mathrm{H}$-atom parameters constrained

\author{
$D_{x}=1.325 \mathrm{Mg} \mathrm{m}^{-3}$ \\ Mo $K \alpha$ radiation \\ Cell parameters from 2262 \\ reflections \\ $\theta=3.2-27.5^{\circ}$ \\ $\mu=0.10 \mathrm{~mm}^{-1}$ \\ $T=120(2) \mathrm{K}$ \\ Block, colourless \\ $0.50 \times 0.30 \times 0.20 \mathrm{~mm}$
}

1869 reflections with $I>2 \sigma(I)$

$R_{\text {int }}=0.036$

$\theta_{\max }=27.5^{\circ}$

$h=-7 \rightarrow 7$

$k=-11 \rightarrow 11$

$l=-24 \rightarrow 22$ 
Table 1

Selected geometric parameters $\left(\AA{ }^{\circ}{ }^{\circ}\right)$.

\begin{tabular}{lrlr}
\hline $\mathrm{N} 1-\mathrm{O} 1$ & $1.2601(15)$ & $\mathrm{N} 1-\mathrm{O} 3$ & $1.2603(14)$ \\
$\mathrm{N} 1-\mathrm{O} 2$ & $1.2404(15)$ & & \\
$\mathrm{O} 1-\mathrm{N} 1-\mathrm{O} 2$ & $120.60(11)$ & $\mathrm{O} 1-\mathrm{N} 1-\mathrm{O} 3$ & $118.85(11)$ \\
$\mathrm{O} 2-\mathrm{N} 1-\mathrm{O} 3$ & $120.54(11)$ & & \\
$\mathrm{C} 12-\mathrm{C} 11-\mathrm{C} 1-\mathrm{N} 2$ & $100.66(14)$ & $\mathrm{C} 1-\mathrm{N} 2-\mathrm{C} 3-\mathrm{C} 4$ & $173.25(11)$ \\
$\mathrm{C} 11-\mathrm{C} 1-\mathrm{N} 2-\mathrm{C} 3$ & $-74.31(14)$ & &
\end{tabular}

Table 2

Hydrogen-bond geometry $\left(\AA,^{\circ}\right)$.

\begin{tabular}{lllll}
\hline$D-\mathrm{H} \cdots A$ & $D-\mathrm{H}$ & $\mathrm{H} \cdots A$ & $D \cdots A$ & $D-\mathrm{H} \cdots A$ \\
\hline $\mathrm{N} 2-\mathrm{H} 2 A \cdots \mathrm{O} 1$ & 0.92 & 1.99 & $2.8855(15)$ & 164 \\
$\mathrm{~N} 2-\mathrm{H} 2 B \cdots{ }^{\mathrm{i}}$ & 0.92 & 1.93 & $2.8299(15)$ & 166 \\
$\mathrm{C} 1-\mathrm{H} 1 A \cdots{ }^{\mathrm{ii}}{ }^{\mathrm{ii}}$ & 0.99 & 2.48 & $3.2652(17)$ & 136 \\
$\mathrm{C} 13-\mathrm{H} 13 \cdots \mathrm{O}^{\mathrm{iii}}$ & 0.95 & 2.52 & $3.4050(17)$ & 156 \\
\hline
\end{tabular}

Symmetry codes: (i) $x-1, y, z$; (ii) $-x+1,-y+1,-z+1$; (iii) $x-\frac{1}{2},-y+\frac{3}{2}, z+\frac{1}{2}$.

The space group $P 2_{1} / n$ was uniquely assigned from the systematic absences. All $\mathrm{H}$ atoms were located from difference maps and then treated as riding atoms, with $\mathrm{C}-\mathrm{H}$ distances of 0.95 (aromatic), 0.98 $\left(\mathrm{CH}_{3}\right)$ or $0.99 \AA\left(\mathrm{CH}_{2}\right)$, and $\mathrm{N}-\mathrm{H}$ distances of $0.92 \AA$, and with $U_{\text {iso }}(\mathrm{H})$ values of $1.2 U_{\text {eq }}(\mathrm{C}, \mathrm{N})$ or $1.5 U_{\text {eq }}($ methyl C).

Data collection: COLLECT (Hooft, 1999); cell refinement: $D E N Z O$ (Otwinowski \& Minor, 1997) and COLLECT; data reduction: DENZO and COLLECT; program(s) used to solve structure: OSCAIL (McArdle, 2003) and SHELXS97 (Sheldrick, 1997); program(s) used to refine structure: OSCAIL and SHELXL97
(Sheldrick, 1997); molecular graphics: PLATON (Spek, 2003); software used to prepare material for publication: SHELXL97 and PRPKAPPA (Ferguson, 1999).

X-ray data were collected at the EPSRC X-ray Crystallographic Service, University of Southampton, England. JC thanks the Consejería de Innovación, Ciencia y Empresa (Junta de Andalucía, Spain) and the Universidad de Jaén for financial support. RA and ER thank COLCIENCIAS and UNIVALLE (Universidad del Valle, Colombia) for financial support.

Supplementary data for this paper are available from the IUCr electronic archives (Reference: SK1877). Services for accessing these data are described at the back of the journal.

\section{References}

Bernstein, J., Davis, R. E., Shimoni, L. \& Chang, N.-L. (1995). Angew. Chem. Int. Ed. Engl. 34, 1555-1573.

Ferguson, G. (1999). PRPKAPPA. University of Guelph, Canada.

Gregson, R. M., Glidewell, C., Ferguson, G. \& Lough, A. J. (2000). Acta Cryst. B56, 39-57.

Hooft, R. W. W. (1999). COLLECT. Nonius BV, Delft, The Netherlands.

McArdle, P. (2003). OSCAIL for Windows. Version 10. Crystallography Centre, Chemistry Department, NUI Galway, Ireland.

Otwinowski, Z. \& Minor, W (1997). Methods in Enzymology, Vol. 276, Macromolecular Crystallography, Part A, edited by C. W. Carter Jr \& R. M. Sweet, pp. 307-326. New York: Academic Press.

Sheldrick, G. M. (1997). SHELXS97 and SHELXL97. University of Göttingen, Germany.

Sheldrick, G. M. (2003). SADABS. Version 2.10. University of Göttingen, Germany.

Spek, A. L. (2003). J. Appl. Cryst. 36, 7-13. 